\title{
Production of mono-, di-, and triglycerides from waste fatty acids through esterification with glycerol
}

\author{
N. A. Mostafa ${ }^{1}$, Ashraf Maher ${ }^{2}$, Wael Abdelmoez ${ }^{2 *}$ \\ ${ }^{1}$ Faculty of Applied Medical Science, Taif University, Taif, KSA \\ ${ }^{2}$ Chemical Engineering Department, Faculty of Engineering, Minia University, Minia, Egypt \\ Email: drengwael2003@yahoo.com
}

Received 10 July 2013; revised 10 August 2013; accepted 25 August 2013

Copyright @ 2013 N. A. Mostafa et al. This is an open access article distributed under the Creative Commons Attribution License, which permits unrestricted use, distribution, and reproduction in any medium, provided the original work is properly cited.

\begin{abstract}
Currently monoglyceride and diglyceride are representing important products, as they have numerous applications such as modifying agents in food and pharmaceutical industries. In this work, the production of these economically value added compounds by estrifying the fatty acids with the glycerol is presented. Effects of various reaction parameters were optimized to obtain high yield of mono, di- and triglycerids. The effects of temperature $\left(180^{\circ} \mathrm{C}\right.$ to $\left.260^{\circ} \mathrm{C}\right), \mathrm{ZnCl}_{2}$ catalyst concentration $(0.1 \%, 0.2 \%, 0.3 \%)$, glycerol to fatty acids molar ratio $(1: 1,1: 2,1: 3,3: 1)$, agitation speeds $(200,500,1000 \mathrm{rpm})$, type of reaction system (opened and closed) and type of fatty acids including oleic and palmatic acids on esterification efficiency of fatty acids were investigated. The optimum conditions of esterification reaction were at temperature $195^{\circ} \mathrm{C}$, molar ratio $1: 1$, amount of catalyst $0.3 \% \mathrm{Zncl}_{2}$, and agitation $500 \mathrm{rpm}$. Analysis of yield showed that at the optimum conditions mondi and triglycerids were produced in high purity, up to $\mathbf{9 9 \%}$. Infrared spectroscopy IR and thin layer chromatograph TLC proved that the final product contains mono, di- and triglycerides.
\end{abstract}

Keywords: Esterification; Fatty Acids; Glycerol; Monoglycerides; Diglycerides; Zinc chloride; Triglycerides

\section{INTRODUCTION}

Soapstock is a by product of the caustic refining of oils and fats. Fatty acids are the main component in the soapstock in the form of sodium salts. These fatty acids could be separated by soapstock acidulation to give waste oils.

*Corresponding author.
Distilled fatty acids could be obtained from waste oils by two processes namely splitting and distillation. These free fatty acids could be used as a starting material for the production of very valuable products such as mono-, diand triglycerides by esterification reaction with glycerol [1]. As consumers become more aware and concerned about the impact of the food they eat and the substances they commonly use on their health and general wellbeing, there is a growing interest in designer lipids. Among the lipid classes, surfactants, such as monoacylglycerols (monoglycerides, MAG), are desired by the food, cosmetic, pharmaceutical and chemical industries [2-5]. Production of tailor-made designer MAG with targeted fatty acids therefore offers promising industrial opportunities. The commercial synthesis of fatty acid esters of glycerol is carried out by two different routes: direct esterification of the fatty acid with the glycerol (Glycerolysis), catalyzed by a homogeneous acid, such as sulphuric or sulfonic acids, or by transesterification of triglycerides and polyalcohol catalyzed by alkaline hydroxides like $\mathrm{NaOH}$, $\mathrm{KOH}$ or $\mathrm{Ca}(\mathrm{OH})_{2}$ and sodium salts of low molecular weight alcohols, such as methanol. The esterification method is best suited for the production of designer MAG because the desired free fate acid (FFA) can easily be selected prior to MAG formation [6]. It could be estimated that approximately $80 \%$ of manufacturing processes use acid catalysts [7]. The complete steps for esterification reaction are demonstrated in Figure 1. The major factors affecting the conversion efficiency of the esterification process are molar ratio of alcohol/oil, amount of catalyst, reaction temperature, catalyst type and stirring speed according to reaction duration $[8,9]$.

Esterification of glycerol and fatty acids was studied under reduced pressure with and without the assistance of various metal chlorides and oxides as catalysts. Also super acids like sulphated zirconia and niobium acid were used as catalyst, for the reason that they could prevent 
${ }^{\mathrm{OH}}$

Glycerol

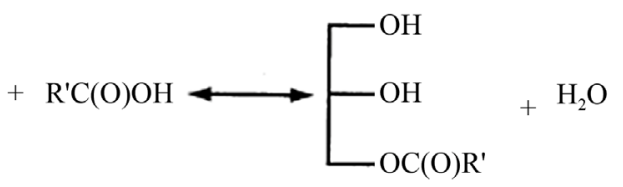

FFA' MAG

Water

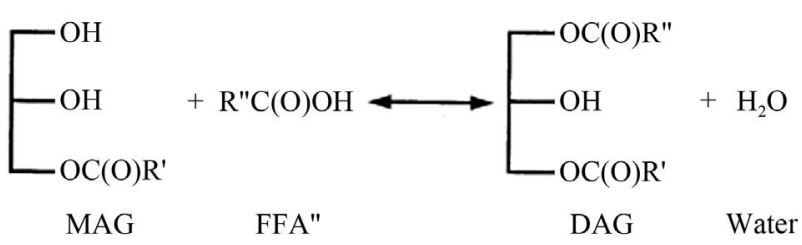

$\left[\begin{array}{l}\mathrm{OC}(\mathrm{O}) \mathrm{R} " \\ \mathrm{OH} \\ \mathrm{OC}(\mathrm{O}) \mathrm{R}^{\prime}\end{array}\right.$<smiles>[R]C(=O)O[Na]</smiles>

DAG
FFA"'

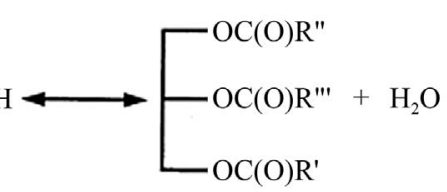

TAG

Water
Figure 1. Estrification reaction.

corrosion, their separation is easy, and also high FFA conversions could be achieved [10].

Recently, heterogeneous acid catalysts have been more widely favored over homogeneous ones since they are more separable and thus easier to recover. There have been only a few studies on non-catalytic esterification and/or transesterification reactions which lead to much simpler purification and environmentally friendly processes [11]. To avoid separation required in homogenous catalytic system, researches have explored the use of heterogeneous catalyst, such as glycerol esterification with lauric and oleic acid using solid cationic resins and zeolitic materials. More recently, mesoporous catalysts containing $\mathrm{SO}_{3} \mathrm{H}$ groups have been reported to be efficient catalysts in the esterification of glycerol with fatty acids, where high yields of mono derivative could be obtained $[7,12]$. The synthesis of triglycerides by enzymatic esterification of polyunsaturated fatty acids (PUFA) with glycerol is well known by using Novozym 435 [13].

In the current work we demonstrate the feasibility of producing mono-, di- and triglycerides from waste fatty acids by direct esterification reaction with glycerol in a solvent free system.

\section{MATERIALS AND METHODS}

\subsection{Materials}

Mixture of fatty acids Saturated and unsaturated were supplied from Al Manaar Company, Alexandria, Egypt. Palmitic acid, ethanol, methanol chloroform, sodium Hy- droxide, potassium iodide, sodium thiosulfate and acetic acid were obtained from El-Nasr Company for chemicals, Cairo, Egypt. Sulfuric acid and phosphoric acid were provided by united company for chemicals, Cairo, Egypt. Distilled water was prepared in our department. ThinLayer Chromatography paper (TLC), Kieselgel 60 f254 precoated plates, E. Merck, Dermastadt, Germany.

\subsection{Equipment}

Esterification reactions were carried out in a laboratory-built apparatus. An apparatus consists of laboratory conical flask $250 \mathrm{ml}$ with $30 \mathrm{ml}$ working volume. Esterification reaction was under atmospheric pressure (opened system), temperature of the reactor was controlled using hot plate (controlled with internal thermostat). All the reactants (fatty acids, glycerol and catalyst) were weighted and charged into the reactor. Then the temperature was increased through adjusting the thermostat. The magnetic stirrer was allowed to operate after 2 - 3 min (to heat up the mixture). After passing the desired reaction time, the reactor was removed from the hot plate. Samples were withdrawn from the reaction mixture for analysis. The reaction mixture was cooled to the ambient temperature by immersing it into a water bath. Also the esterification process in closed system was investigated, where all the reactors were isolated.

\subsection{Optimum Conditions}

Several reaction conditions were optimized including temperature, reaction time, type of catalyst, concentration of catalyst and molar ratio of glycerol to free fatty acids. The studied reaction temperatures were from $180^{\circ} \mathrm{C}$ to $260^{\circ} \mathrm{C}$. The molar ratios of glycerol to fatty acids were 1:3, 1:2, 1:1 and 3:1. Concentrations of catalyst were $0.0 \%, 0.1 \%, 0.2 \%$, and $0.3 \%$. Effect of agitation speeds were in the range of $100 \mathrm{rpm}$ to $1000 \mathrm{rpm}$.

\subsection{Reversible Reaction}

Three runs were conducted to study the effect of the reverse reaction of esterification. Reverse reaction experiments were run at $195^{\circ} \mathrm{C}$ for 60 min using $1: 1$ molar ration without using a catalyst. To find out the best way of demolishing the effect of the reverse reaction on the overall yield of the esterification, the reaction mixture was rapidly cooled down by three different mechanism using refrigeration, water cooling, or air cooling. Then the yield of the esterification was measured in each case to investigate the conversion in each sample.

\subsection{Analytical Methods}

\subsubsection{Determination of the Fatty Acids Conversion}

Titration method was selected for the determination of 
the fatty acids conversion during the esterification reaction because it was simple and efficient analytical method that could be performed without the need for highly specialized equipment [14].

Five grams of the sample at time intervals was dissolved in ethanol and phenolphthalein indicator was used to determine the $\mathrm{pH}$ change during esterification reaction. The titration was carried out against aqueous solution of $0.1 \mathrm{~N} \mathrm{KOH}$. Acid value (A.V) was determined according to the equation given below:

$$
A . V=\frac{56.1 * N * V}{M} \mathrm{mg} \mathrm{KOH} / \mathrm{g} \text { oil }
$$

where:

$N$ : normality of $\mathrm{KOH}$ solution

$V$ : the volume of solution employed for titration, $\mathrm{ml}$

$M$ : weight of fatty acids sample, $g$

The conversion of FFA was calculated by the following equation:

$$
\text { F.F.A. conversion } \%=\frac{A_{i}-A_{t}}{A_{i}} * 100
$$

Where $A_{i}$ is the initial acidity of the mixture and $A_{t}$ acidity at any time, $t$.

\subsubsection{Thin-Layer Chromatography for the Produced Glycosides}

TLC was used to identify the types of glycrides produced during the esterification reaction (i.e mono, di or triglycerides). TLC experiments were carried out by dissolving one drop of the esterification products into $0.5 \mathrm{ml} \mathrm{mix-}$ ture of chloroform and methanol (9:1). Then, a drop from the final mixture was applied over the TLC paper immersed into a 100 ml-beaker containing $10 \mathrm{ml}$ of a mixture of chloroform and methanol (9:1) which allows a contact between the edges of the TLC paper with the solvent mixture. The TLC paper was allowed to stand until the solvent reach a level which must be just below the end line. Then, the TLC paper was dried and the bands of the different produced glycerides were detected under UV lamp. In some cases, the bands were not clearly appearing under the UV lamp. Accordingly, the TLC paper was exposed to an iodine vapor which allows a direct visualizing of the band by naked eye.

\section{RESULTS AND DISCUSSION}

Monoglyceride, diglyceride and triglyceride were the major products obtained in this study. First, it was necessary to optimize the esterification conditions. To find out the optimum esterification conditions, the esterification process was carried out under different operating conditions at any time only one parameter was changing while the other parameters were kept constant.

\subsection{Effect of Type of the System}

To investigate the effect of type of the system on the esterification yield, the same procedures described above were followed by applying both closed and opened systems (isolated and atmospheric systems). The esterification reactions were carried out using molar ratio of 3:1 (glycerol to fatty acids) at $180^{\circ} \mathrm{C}$ for $510 \mathrm{~min}$. Figure 2 shows the effect of both systems on the obtained estrification yield. The results indicated that the closed system and the opened system were come to equilibrium point at nearly the same time. However in the opened system the conversion (91\%) was higher than that obtained by closed system (72\%). Consequently it could be concluded that the opened system based process is more efficient than the closed one. This finding maybe due to the presence of the side reactions products in the estrification reactor inhibit the reaction to be proceed, therefore when these by products allowed to get out from the reactor, favorable products formation could be obtained.

\subsection{Effect of Temperature and Time}

Both temperature and time are having major effects on the conversion of the esterification process. Accordingly, they were studied and optimized together. The obtained results showd that that by increasing the reaction temperature, the reaction conversion increases rapidly. Figure 3 shows that after $20 \mathrm{~min}$, the conversion reached $99 \%$. However, the energy consumed was very high $\left(260^{\circ} \mathrm{C}\right)$ which is not practical from the economic point of view. Therefore another esterification reaction was carried out within a temperature range of $180^{\circ} \mathrm{C}-210^{\circ} \mathrm{C}$ as shown in Figure 4. The results revealed that by increasing the

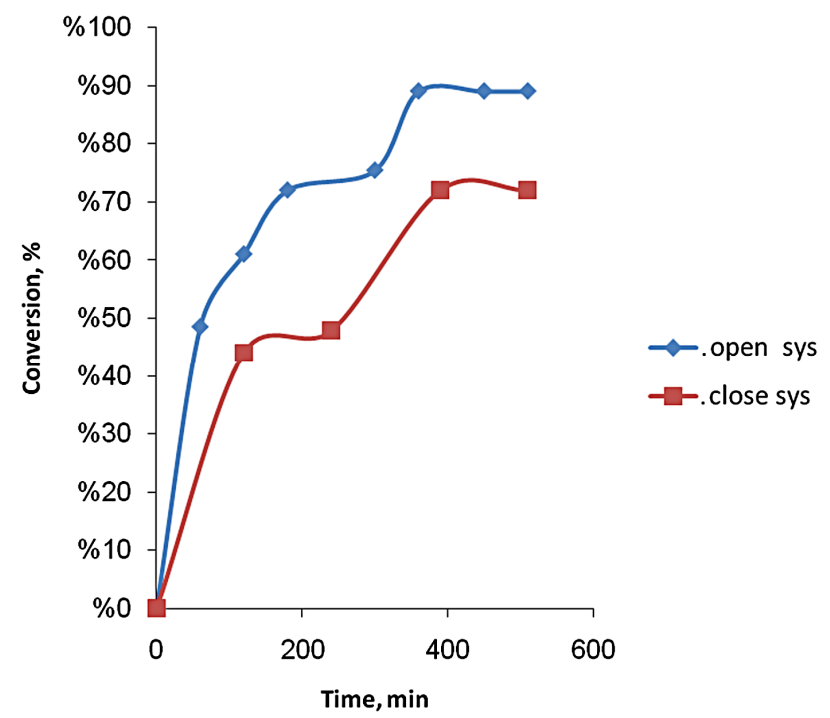

Figure 2. Effect of the type of esterification system (opened system \& closed system) at $180^{\circ} \mathrm{C}, 3: 1$ molar ratio and $510 \mathrm{~min}$ of the unsaturated fatty acid. 


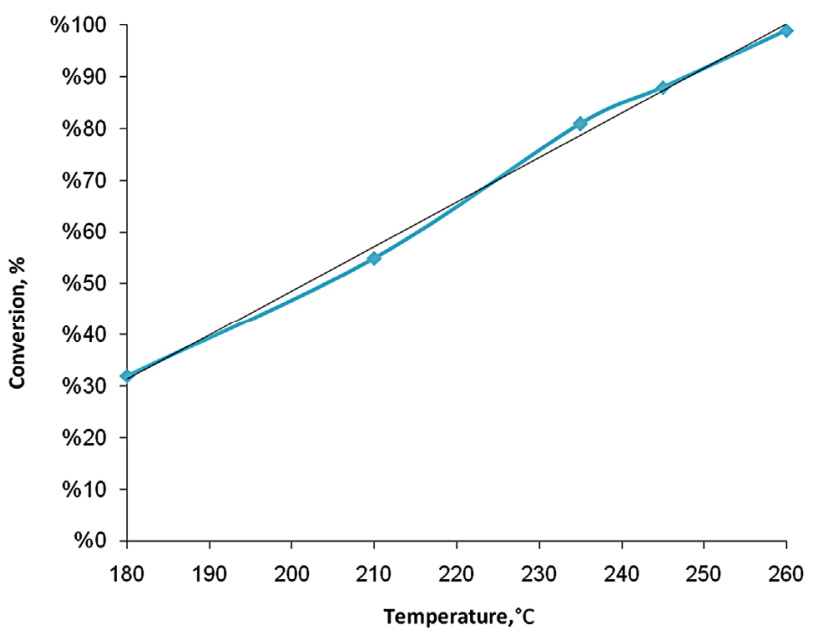

Figure 3. Effect of different temperatures on the esterification yiled of saturated fatty acid after $40 \mathrm{~min}$ and 3:1 molar raio (gly:fat).

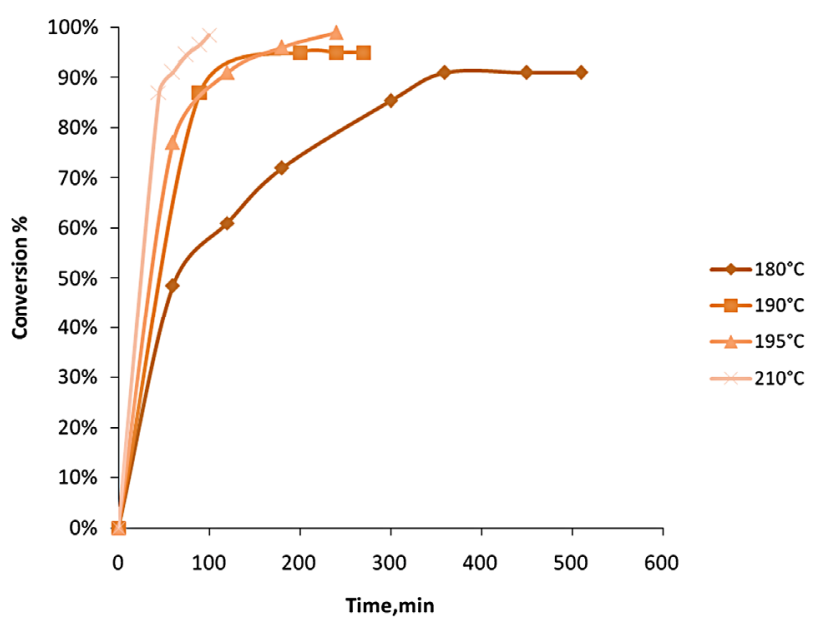

Figure 4. Effect of temperature at 3:1 gly:fat molar ratio on the esterification of unsaturated fatty acid.

esterification time, the esterification yield increased up to a maximum conversation. To determine the optimum temperature of esterification process, not only the maximum yield of esterification should be considered but also the time required to reach the reaction temperature was taken into account. Heating time to reaction temperature was certainly longer and energy consumption was surely greater for higher reaction temperature. Consequently, a faster reaction at a lower temperature is desirable. From this economical point of view, the optimum temperature for the esterification was found to be $195^{\circ} \mathrm{C}$ at which the conversion reached up to $99 \%$.

\subsection{Effect of Molar Ratio on the Esterification Yield}

The second studied parameter was the optimum esterification molar ratio (glycerol:fatty acids). In this part, all experiments were carried out at the optimum obtained temperature $\left(195^{\circ} \mathrm{C}\right)$. The esterification process was carried out at 1:1, 1:2, 1:3 and 3:1 (glycerol to fatty acids). As shown in the Figure 5, it could be easily concluded that 1:1 molar ratio gave the maximum conversion under the required lower amount of raw material which in turn reduces the running cost of the process.

\subsection{Effect of the Concentration of Catalyst on the Esterification Yield}

After investigating the effect of temperature, time and molar ratio without catalyst, the effect of concentration of the catalyst $(0.1 \%, 0.2 \%$, and $0.3 \%)$ on the esterification yield under optimum temperature of $195^{\circ} \mathrm{C}$ and 1:1. molar ratio was investigated. Figure 6 shows the effect of catalyst percentage on the esterification yield. As shown from the figure, by increasing the catalyst concentration, the time required to reach the maximum conversion decreases. So that $0.3 \%$ (by weight) $\mathrm{ZnCl}_{2}$ was considered to be the optimum dose, where the maximum yield of

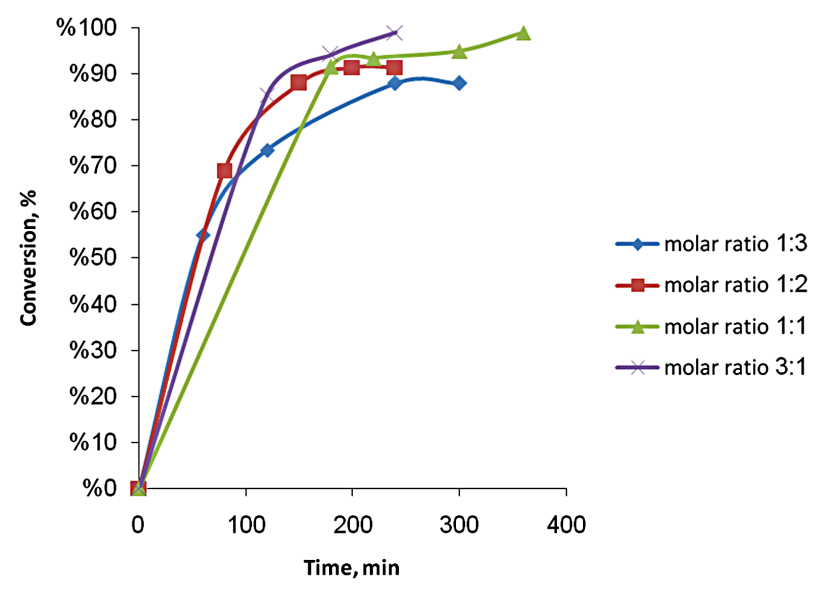

Figure 5. Effect of glycerol:fatty acid molar ratio on the esterification of unsaturated fatty acid with glycerol at $195^{\circ} \mathrm{C}$.

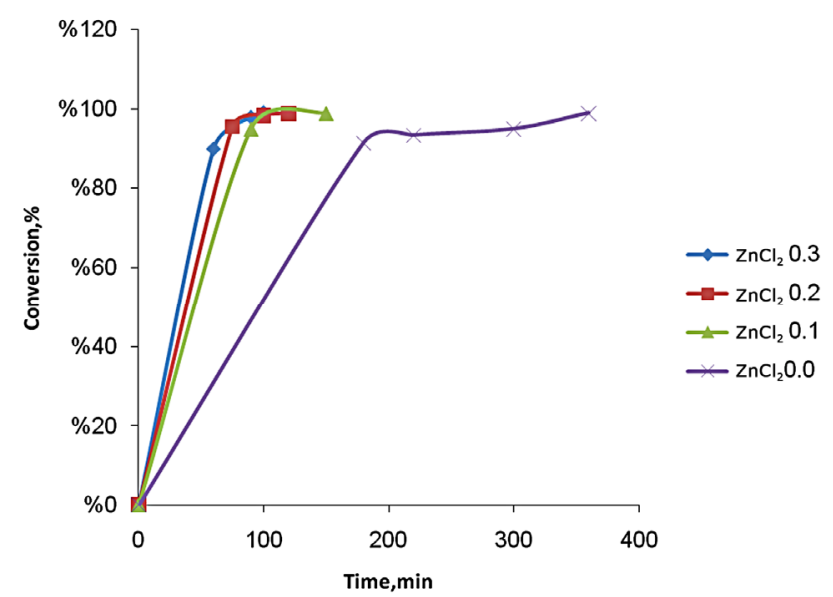

Figure 6. Effect of the concentration of catalyst on the esterification yield at optimum temperature $\left(195^{\circ} \mathrm{C}\right)$. 
99\% could be obtained after 100 min. Further increasing in the catalyst concentration will make the downstream processes including catalyst separation more difficult.

\subsection{Effect of Degree of Agitation (rpm)}

To investigate the effect of the degree of agitation (rpm), the esterification process was carried out at different agitating speeds $(100,500$ and $1000 \mathrm{rpm})$ at $195^{\circ} \mathrm{C}, 1: 1$ fatty acids to glycerol and without catalyst. The results are presented in Figure 7. As shown from the figure the maximum conversion of $99 \%$ was obtained at $500 \mathrm{rpm}$.

\subsection{Effect of the Reverse Reaction}

Reverse reaction effect was stopped using three different cooling mechanisms as described in the method part. The results were presented in Figure 8. As shown in the figure, the yield of esterification were $92 \%, 90 \%$, and $88 \%$ for reactions cooled down by refrigerator, cooling water and air cooling, respectively. The rapid cooling of the reaction mixture prevents (through low temperature) the reversible reaction, which in turn keeping the conversion. Accordingly, by decreasing the cooling temperature the effect of reversible reaction is minimized.

\subsection{Effect of the Type of Fatty Acids on the Esterification Yield}

In this part of the study, all experiments were carried out at the optimum obtained conditions including temperature $\left(195^{\circ} \mathrm{C}\right)$, molar ratio (1:1) and different types of fatty

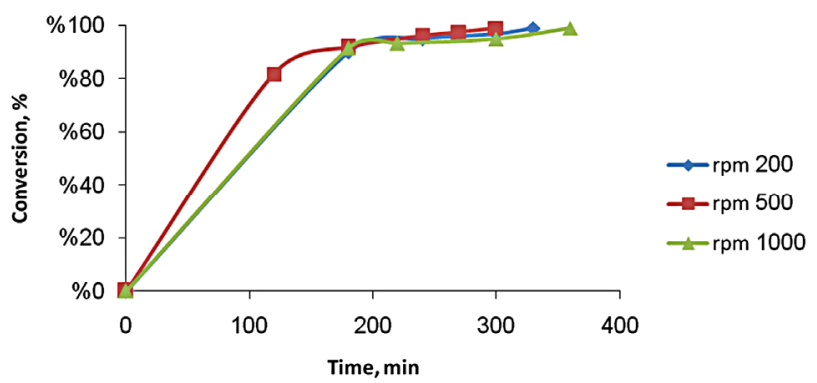

Figutr 7. Effect of the degree of agitation at $195^{\circ} \mathrm{C}, 1: 1$ (gly:fat) molar ratio.

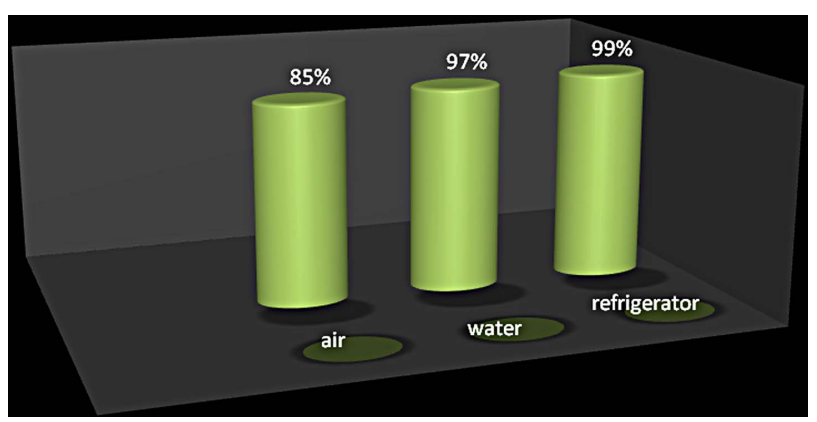

Figure 8. Effect of reversible reaction at optimum temperature. acids (oleic acid, stearic acid and palmitic acid Figure 9 shows the effect of the type of fatty acids on the esterification yield. The results showed that the yield of esterification recorded a maximum conversion at time of 360 , 240, $210 \mathrm{~min}$ in case of oleic acid, stearic acid and palmitic acid, respectively. From these results it could be concluded that the fatty acid chain length and the degree of unsaturation are having a considerable effect on the esterification reaction. Since long chain and unsaturated fatty acids need higher reaction time compared with the smaller chain and saturated fatty acids.

\subsection{Esterification Reaction Using the Optimized Conditions}

In this part, the esterification of free fatty acids was performed under the obtained optimum conditions. The time course of the esterification was measured and shown in Figure 10. The data showed that the maximum conversion (99\%) was obtained after 100 min (instead of 180 min in the temperature effect experiments). Accordingly the esterification processes was achieved in a considerably short time and lower temperature. A sample was taken for IR and TLC analysis to prove the composition of the obtained esterification products. Figure 11 shows

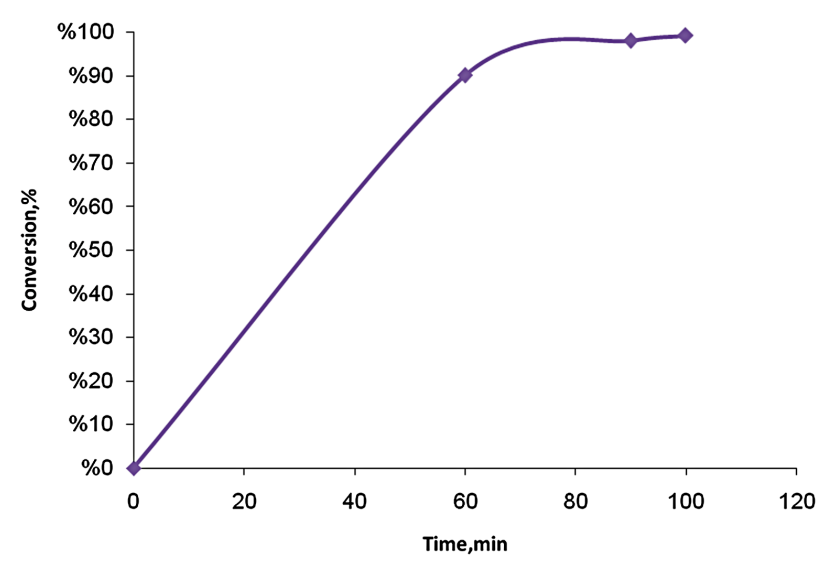

Figure 9. The esterification yield under the optimum condition (195 ${ }^{\circ} \mathrm{C}, 100 \mathrm{~min}, 0.3 \% \mathrm{ZnCl}_{2}$, $500 \mathrm{rpm}$ ).

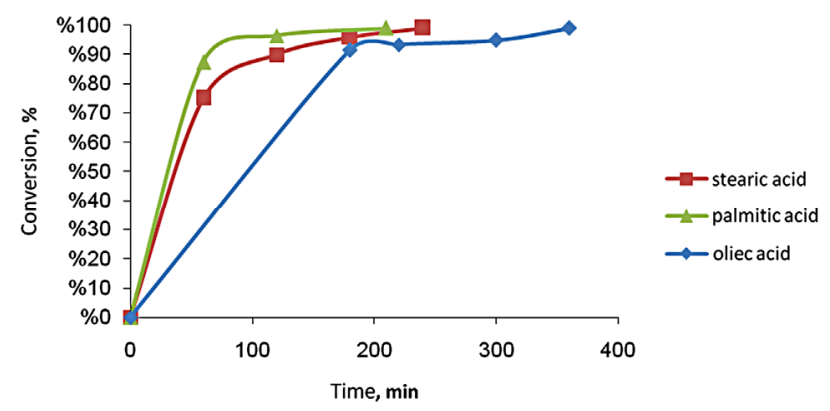

Figure 10. Effect of degree of saturation and number of atoms of the fatty acids on the esterification reaction at optimum temperature. 
the IR analysis, the results proved the existance of the carbonyl group (at wavenumber 1738.96 of the ester formation [15].

Figure 12 shows the TLC paper plate of both estrfied and free fatty acid. The results showd the existence of the three main products of monoglyceride, diglyceride, and triglyceride.

Now let us compare the results obtained in this study with others. Lilis Hermida [16] used a mesoporous catalyst in order to catalyzing the estrification reaction, the optimum conditions obtained were, $5 \%$ catalyst, 2:1 glycerol:fatty acid and $750 \mathrm{rpm}$ which were higher than that obtained in this study. Furthermore the conversion obtained was $95 \%$ which was less than the $99 \%$ obtained in this study. Such a result indicated the effectiveness of the proposed route for production of mono-, di- and triglycerides.

Consequently, the esterification performed in the present work will make two major benefits; firstly, it will make the production of biodiesel more competitive with the existing diesel fuel market. Secondly, it will produce which is the most important emulsifier used in food industry.

\section{PROCESS SIMULATION}

The last step of this article was building an estrification plant with a capacity of 100 ton of fatty acids/day using ASPEN HYSYS 2006 as shown in Figure 13. As demonstrated in the figure the process starts with a feeding pump (P-100) which was used for transferring the free fatty acids to the esterification reactor (convertor type reactor, CRV-100) through a heat exchanger (E-100) equipped with control valve (VLV-102). Glycerol was transferred to mixing tank through control valve (VLV100) and zinc chloride was mixed with glycerol in the same mixing tank (V-100). Then the mixture was pumped to reactor (CRV-100) through a transfer pump (P-101) equipped with a flow control (VLV-101). The product was cooled by the exchanger (E101). The resulting mixture was transferred to a washing tank (V-101). The washing was carried out using fresh water. Then, the washed mixture was transferred to a settling tank (V-102) using a control valve (VLV-103). The mixture inside the settling tank is divided into two phases. The first phase is composed mainly of esterified fatty acids and the second phase is composed mainly of catalyst, glycerol and water. The first phase was pumped through control (VLV-104) to a fractionation tower ( $\mathrm{T}-100)$ equipped with ten stages fractionating the feed into glycerol from the top and esterified fatty acids from the bottom. The results of the simulation were summarized in Table 1. As shown in Table 1 the yield of the final product was found to be

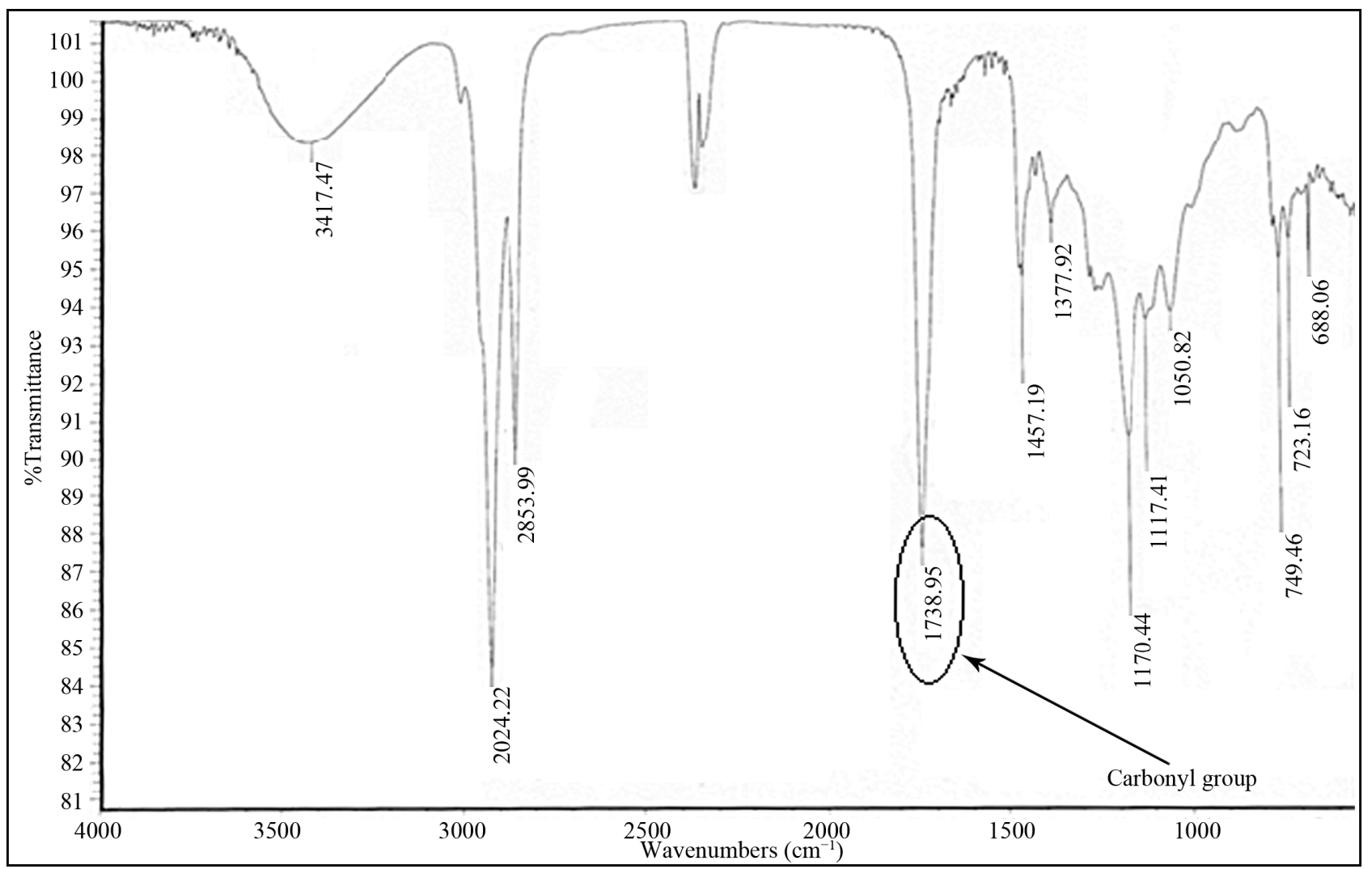

Figure 11. IR analysis of esterification unsaturated fatty acids. 


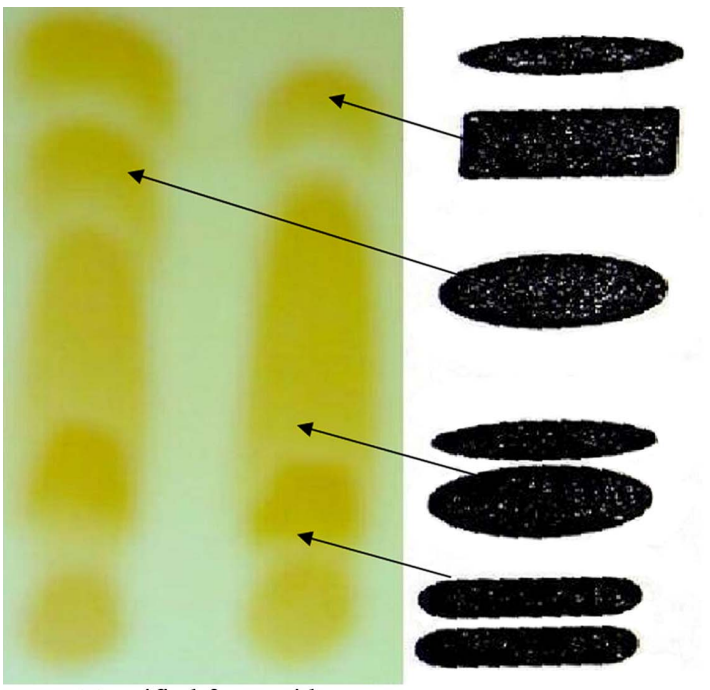

Esterified fatty acid
Cholesterol ester

Triglycerides

Free fatty acids

Cholesterol

Diglycerides

Monoglycerides

Phospholipids origin

Figure 12. TLC analysis of esterified and non esterified fatty acids.

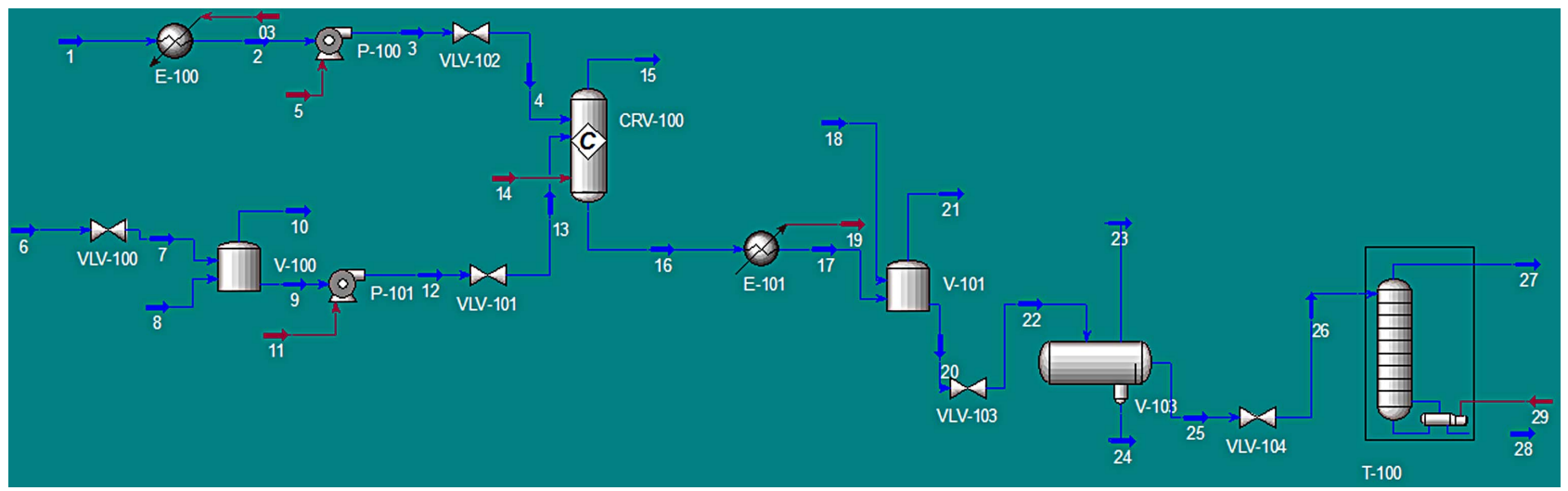

Figure 13. Ester production plant from fatty acids and glycerol.

Table 1. Results of the simulation.

\begin{tabular}{|c|c|c|}
\hline \multicolumn{3}{|c|}{ Feed } \\
\hline \multirow{2}{*}{ Free fatty acid } & $\mathrm{M}^{3} / \mathrm{hr}$ & 4.9 \\
\hline & Mass\% & $99 \%$ \\
\hline \multirow{2}{*}{ Glycerol make up } & $\mathrm{m}^{3} / \mathrm{hr}$ & 1.05 \\
\hline & Mass\% & 99 \\
\hline \multirow{2}{*}{$\mathrm{ZnCl}_{2}$} & $\mathrm{~kg} / \mathrm{hr}$ & 16.5 \\
\hline & Mass\% & 99 \\
\hline \multirow{2}{*}{ Washing water } & $\mathrm{m}^{3} / \mathrm{hr}$ & 1 \\
\hline & Mass\% & 100 \\
\hline \multicolumn{3}{|c|}{ product } \\
\hline \multirow{2}{*}{ Fatty acid ester } & $\mathrm{m}^{3} / \mathrm{hr}$ & 5.09 \\
\hline & Mass\% & 96 \\
\hline \multirow{2}{*}{ glycerol } & $\mathrm{m}^{3} / \mathrm{hr}$ & 0.4267 \\
\hline & Mass\% & 72.7 \\
\hline
\end{tabular}

$96 \%$ ester and $4 \%$ glycerol at the bottom of the distillation tower. On the other hand, at the top of the tower it was recovered for about $73 \%$ glycerol.

Copyright @ 2013 SciRes.

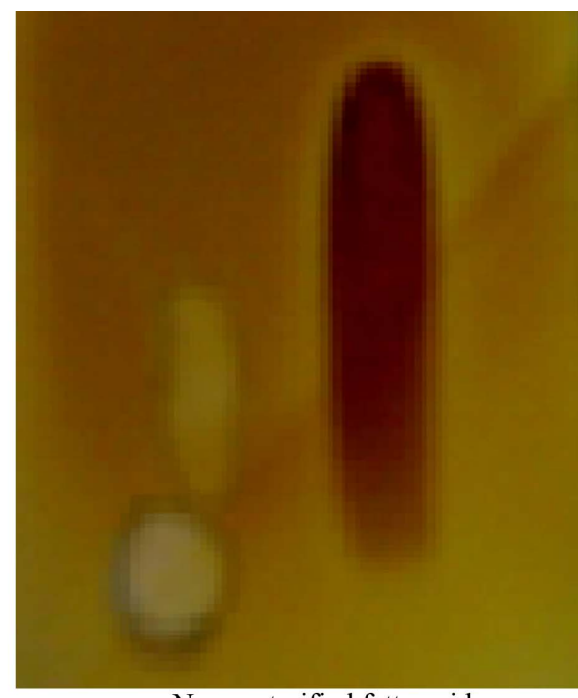

None esterified fatty acid

(2)

\section{REFERENCES}

[1] Isabel, D., Federico, M., Joaquin, P. and Enrique, S. (2003) Synthesis of MCM-41 materials dialkyl silane groups and their catalytic activity in functionalised with the esterification of glycerol with fatty acids. Applied Catalysis A: General, 242, 161-169. doi:10.1016/S0926-860X(02)00501-X

[2] Anonymous (2006) Lubricant compositions. Research Disclosure, 690.

[3] Fernandez, A.M., Held, U., Willing, A. and Breuer, W.H. (2005) New green surfactants for emulsion polymerization. Progress in Organic Coatings, 53, 246-255. doi:10.1016/j.porgcoat.2004.12.011

[4] Eccleston, G.M. (1997) Functions of mixed emulsifiers and emulsifying waxes in dermatological lotions and creams. Colloids and Surfaces A: Physicochemical and Engineering Aspects, 123-124, 169-182. doi:10.1016/S0927-7757(96)03846-0

[5] Garti, N. (1999) What can nature offer from an emulsifier point of view: Trends and progress? Colloids and Surfaces A: Physicochemical and Engineering Aspects, 152, 
125-146. doi:10.1016/S0927-7757(98)00621-9

[6] Guner, F.S., Sirkecioglu, A., Yilmaz, S., Erciyes, A.T. and Erdem-Senatalar, A. (1996) Esterification of oleic acid with glycerol in the presence of sulfated iron oxide catalyst. Journal of the American Oil Chemists' Society, 73, 347-351. doi:10.1007/BF02523429

[7] Moquinp (2008) Hydrolysis, esterification and glycerolysis of lipids in supercritical carbon dioxide media. Proquest Dissertations and Theses, University of Alberta.

[8] Farag, H., Azza, M. and Taha, N.A. (2011) Optimization of factors affecting esterification of mixed oil with high percentage of free fatty acid. Fuel Processing Technology, 92, 507-510. doi:10.1016/j.fuproc.2010.11.004

[9] Chetpattananondh, P., Rukprasoot, J., Bunyakan, C. and Tongurai, C. (2005) Glycerolysis of crude glycerol derived from biodiesel process. PSU-UNS International Conference on Engineering and Environment, Novi Sad, 19-21 May 2005.

[10] Zbay, N.O., Oktar, N. and Alper Tapan, N. (2008) Esterification of free fatty acids in waste cooking oils (WCO): Role of ion-exchange resins. Fuel, 87, 1789-1798. doi:10.1016/j.fuel.2007.12.010

[11] Hyun, J., Soo Hyun, K., Seok, W. and Yeong-Koo, Y. (2012) A single step non-catalytic esterification of palm fatty acid distillate (PFAD) for biodiesel production. Fuel,
93, 373-380. doi:10.1016/j.fuel.2011.08.063

[12] Sakthivel, A., Nakamura, R., Komura, K. and Komura, Y. (2007) Esterification of glycerol by lauric acid over aluminium and zirconium containing mesoporous molecular sieves in supercritical carbon dioxide medium. Journal of Supercritical Fluids, 42, 219-225. doi:10.1016/j.supflu.2007.03.012

[13] Cramer, J., Dueholm, M., Nielsen, S., Pedersen, D. and Cramer, J.F. (2007) Controlling the degree of esterification in lipase catalysed synthesis of xylitol fatty acid esters. Enzyme and Microbial Technology, 41, 346-352. doi:10.1016/j.enzmictec.2007.03.001

[14] Egyptian Standard Specifications Codex 210/1999 m. k. m 49-6/2005.

[15] Vlachos, N., Skopelitis, Y., Psaroudaki, M., Konstantinidou, V., Chatzilazarou, A. and Tegou, E. (2006) Applications of fourier transform-infrared spectroscopy to edible oils. Analytica Chimica Acta, 573-574, 459-465. doi:10.1016/j.aca.2006.05.034

[16] Hermida, L., Abdullah, A.Z. and Mohamed, A.R. (2011) Synthesis of monoglyceride through glycerol esterification with lauric acid over propyl sulfonic acid post-synthesis functionalized SBA-15 mesoporous catalyst. Chemical Engineering Journal, 174, 668-676. 